\title{
Risk management and its methodological support in the performance economy
}

\author{
W. E. Schroeder \\ Department of Economics and Business Management, \\ Montanuniversität Leoben, Austria
}

\begin{abstract}
The increasing complexity and dynamism of the business environment but also the compulsion of raising efficiency, which is always associated with making internal systems lean, forces the need for a comprehensive and holistic risk management system. Therefore, besides the financial perspective, we also have to look at value-added production and service processes with their resulting risks. A well functioning efficient risk management in performance economy requires a systematic methodical support in the various phases of the risk management process. A study carried out by the Department of Economics and Business Management, Montanuniversität Leoben shows how permeated these methods and instruments are when used in industrial practice. Data collection was conducted in the years 2010 and 2011, with a written questionnaire in an online survey of 850 German and Austrian companies. In general, the focus of the survey was aimed at the prevailing understanding of risk, the importance of key risk areas and the risk management process in the performance economy. Here, above all, the permeation of the methodological support in the strategic and operational risk management process has been studied. The aim of this research was to investigate: How is the dominant risk-managementunderstanding constituted in operational practice and what are the risk areas having the greatest relevance? Which policies, laws, regulations and standards are geared to operational practice? How far has the set of different instruments and tools permeated the risk management process in operational practice? The present study shows that just in that field a systematic and consistent application of instruments and tools in the risk management process is lacking in operational practice. The methodological gaps often lead to not closing risk management process loops and to a missing connection from an operational to a strategic management level. Here it is important to use a matched set of instruments and
\end{abstract}


tools in order to ensure a closed risk management process, which in turn minimizes the uncertainty in dealing with risks.

Keywords: risk management process, performance economy, methodological support.

\section{Introduction}

Since future actions always involves uncertainty and potential risks and opportunities in advance never be estimated accurately, it must have a suitable risk management (RM) to ensure the handling of threats and opportunities. Only a conscious examination of risks allows a systematic management of a company's risk portfolio.

Basically, business risks can be divided into three main categories: financial risks, performance-related risks and risks of corporate governance [1]. The performance-related risks include processes of procurement, production and maintenance, sales as well as research and development [2].

A survey conducted by Nevries and Strauß [3] in major German companies shows, that the monitoring of performance-related risks especially is a key aspect of RM. A PricewaterhouseCoopers study on the financial and economic crisis of 2008 and 2009 says that six out of ten companies have adjusted their RM after crisis or plan changes [4]. A trend in recent years shows that the less the isolated consideration and protection of individual risks is in focus, the more an enterprise-wide, integrated RM is demanded.

The awareness has found that RM solely based on financial ratios is not sufficient to cover all facets of this topic. On the one hand, financial ratios only allow us to look into the past of the company's perspective, and on the other significant risk areas, such as changes in statutory provisions and regulations, technology projections or natural disaster as well as soft factors like leadership, communication or the corporate culture are not considered by financial rations.

Already Klügl [5] stresses that there is a methodological need especially to establish a high performance RM in both the strategic and the operational level of a management system but points out, at the same time, the indecisiveness in the use of instruments and techniques in corporate practice. A selection of supporting instruments and techniques in the performance-related RM process is shown by Wildemann [6].

A well-functioning efficient performance-related RM requires the systematic use of instruments and techniques to support each stage of the RM process. A study conducted by the Department of Economics and Business Management, Montanuniversität Leoben, based on a sample of about 70 companies shows, how permeated these instruments and techniques are in operational practice.

\section{Research methodology}

Data collection was carried out in 2010 and 2011. The written questionnaire sent in an online survey to 850 German and Austrian companies (response rate $8.5 \%$, equal to 72 completed questionnaires). The questionnaire, which was used in the 
study, consists of 21 main questions, covering the areas: RM process; regulations; instruments and techniques; documentation and IT-support. Mainly members of senior management as well as people who are responsible for the $\mathrm{RM}$ process, were addressed. The responding companies were $71 \%$ from the industrial and $29 \%$ from the service sector. A large proportion of companies were mainly from the iron and steel industry $(27 \%)$, the metal-processing industry $(24 \%)$ and the chemical industry $(12 \%)$. On the services sector, IT and telecommunications (with about 10\%) was most strongly represented. About $10 \%$ of returns were attributable to small and medium enterprises (SME) but the representative proportion of responding companies had more than 250 employees and an annual turnover of more than 50M EUR.

The focus of the survey is aimed on the prevailing understanding of risk in practical business, the importance of key risk areas and in particular on the RM process. The aim of this study is therefore to examine:

- The dominant RM-understanding and the areas of risk with the greatest relevance in practical business;

- On which policies, laws, regulations and standards is practical business oriented;

- How far has the set of various instruments and techniques permeated the current RM process in practical business.

\section{Risk management appreciation}

Risk management appreciation was examined to assess what risks are critical for companies. In general, economical and technological risks as well as risks on sales and procurement are classified as essential. On the other hand, sociopolitical risks (e.g. election returns, laws) have minor relevance. Also risks in the labor market are attributed a somewhat lesser importance. From a functionoriented view risks in the production area are of high relevance (see table 1).

Table 1: $\quad$ Importance of major risk areas (according to rank).

\begin{tabular}{|l|c|}
\hline \multicolumn{1}{|c|}{ Areas of risks } & Order of priority \\
\hline economics (cyclical, structural, ...) & 1 \\
\hline sales market (pricing, new orders) & 2 \\
\hline technology (R\&D) & 3 \\
\hline procurement market (supplier, stocks) & 4 \\
\hline production & 5 \\
\hline management (corporate strategies) & 6 \\
\hline employee (age pyramid, labor turnover rate, ...) & 7 \\
\hline capital market (interest rates, exchange rates, etc.) & 8 \\
\hline project management & 9 \\
\hline distribution & 10 \\
\hline machine equipment (energy, environmental impact, ...) & 11 \\
\hline product range (length and depth) & 12 \\
\hline logistics & 13 \\
\hline administration & 14 \\
\hline socio-politics (election returns, laws, ...) & 15 \\
\hline
\end{tabular}




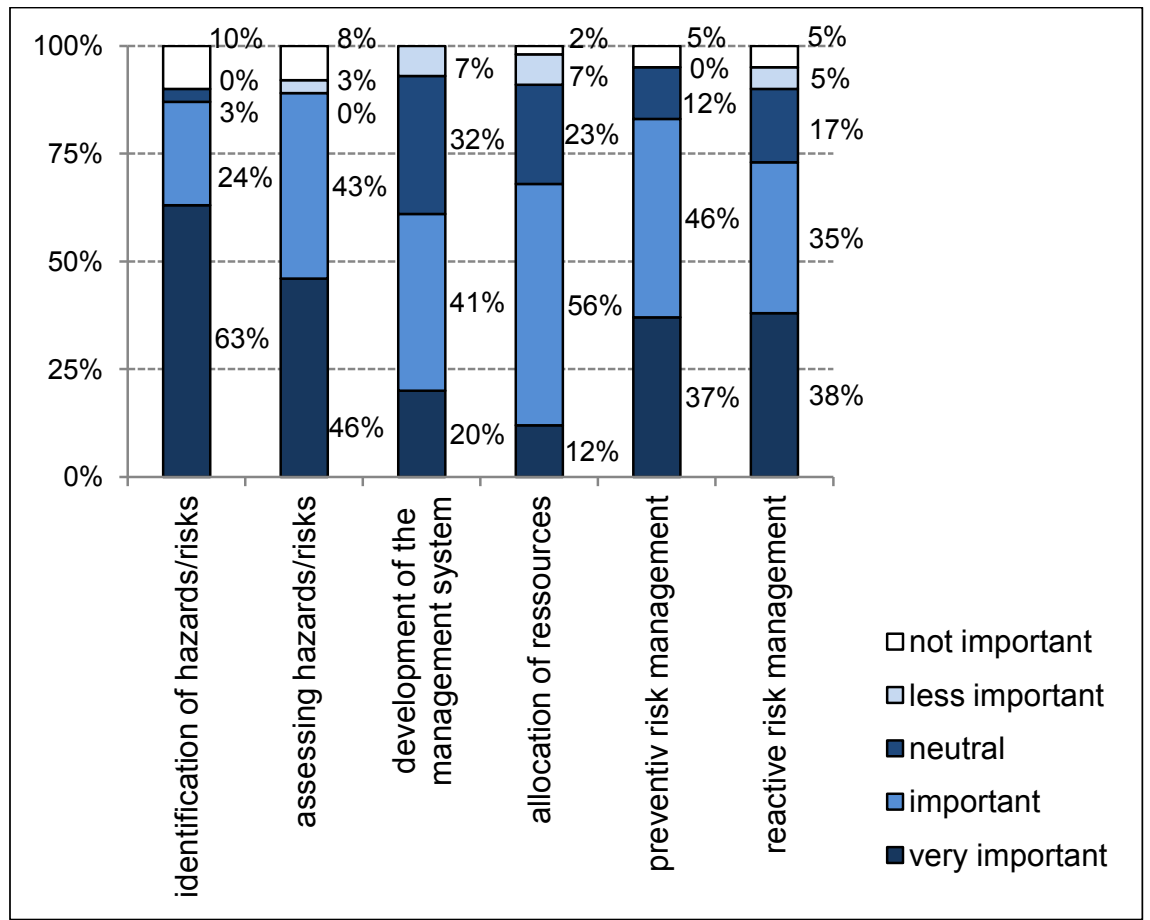

Figure 1: Assessing the importance of risk-relevant factors.

In the survey, the relevance of significant aspects of the RM process was also analyzed. Nearly $90 \%$ of questioned companies see the risk identification and assessment of hazards as an important or very important step in the RM process. Less important is the further development of the management system. The provision of resources for the area RM is classified only by two thirds of the respondents as important or very important. A preventive or reactive RM was judged in about $38 \%$ of the respondents as very important and prevention would be given a total of more importance than reaction.

\section{Focus on regulations}

About 100 different regulations and standards currently exist to risk and RM. Due to the constantly changing business environment and the ongoing renewal of laws, policies and standards (e.g. Basel III), also a consideration with regard to the use of regulations is interesting (in this context, the term regulation sub summates policies, laws and standards). In the survey, the results are divided as expected into the relevant German (Act for Control and Transparency in the Corporate Sector - KonTraG - with 15\%) and Austrian laws (Company Law Amendment Act - ÜRÄG - 29\%). The use of the COSO standard (Committee of Sponsoring Organizations of the Treadway Commission) $(27 \%)$ is undoubtedly 
linked to the anchorage in the Austrian URÄG. With 20\%, the RM standard ISO 31000 and with $17 \%$ the corresponding Austrian standard ONR 49000ff are in use. Also frequently mentioned is the use of the ISO 27000, which represents the current standard for information security management systems. Only the Sarbanes-Oxley Act (SOX) would be barely considered in Germany and Austria (see Figure 2).

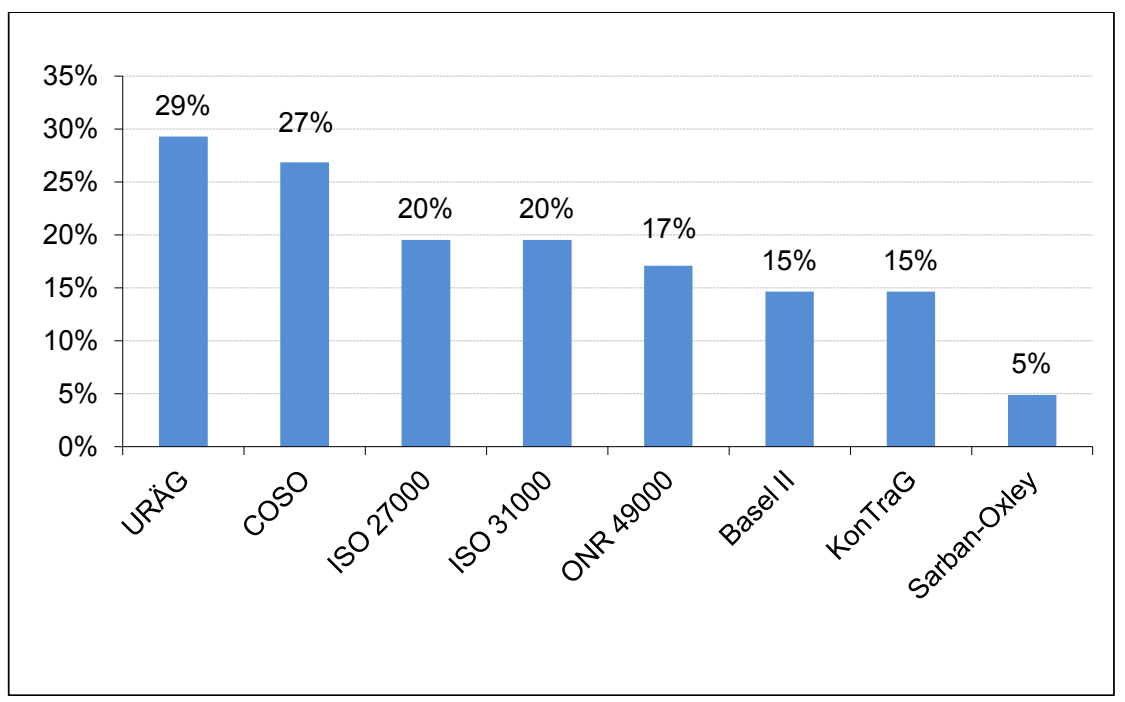

Figure 2: Used regulations in the RM process.

\section{Instruments and techniques used in the performance-related $R M$ process}

The strategic dimension of the risk management process mainly includes the formulation of objectives as well as a derived risk strategy in accordance with corporate risk policy. Strategic risks are particularly those that weaken the market position and constitute a threat to the company's future development. Instruments and tools in the strategic RM have the primary task of

1. an environment and system analysis,

2. a reflection of the risk landscape,

3. and the implementation of an appropriate risk strategy,

$59 \%$ of companies declare that they systematically identify risks to predetermined methods. $71 \%$ of the companies make this determination on a regular basis and for $51 \%$, the results of the risk assessment is a main input for the corporate strategy planning process. The most common method for environment and system analysis is the opportunity-hazards analysis (59\%). Significantly less use for this task has the scenario technique (20\%). To reflect 
the whole risk landscape, the SWOT analysis is used most often. The portfolio methodology, (which includes the risk map) will be applied by only $15 \%$ of the companies. The implementation of the appropriate risk strategy will be primarily supported by a Balanced Scorecard (BSC). Hardly used, however, is the Quality Function Deployment (QFD).

In summary, it can be stated that both the use of instruments of strategic management (portfolio, SWOT) as well as tools whose origin lies in quality management (QFD) are in practical application to support the RM process methodically (see figure 3). Risks are often identified, but an analytical examination of the dependencies between internal strengths and weaknesses with the link to the results of the environmental analysis and a derivation of fields of action as well as a prioritization is much less systematically and methodically based. Even less (only about a third of the surveyed companies) set up a methodbased system in the process of formulating objectives and derive an appropriate risk strategy.

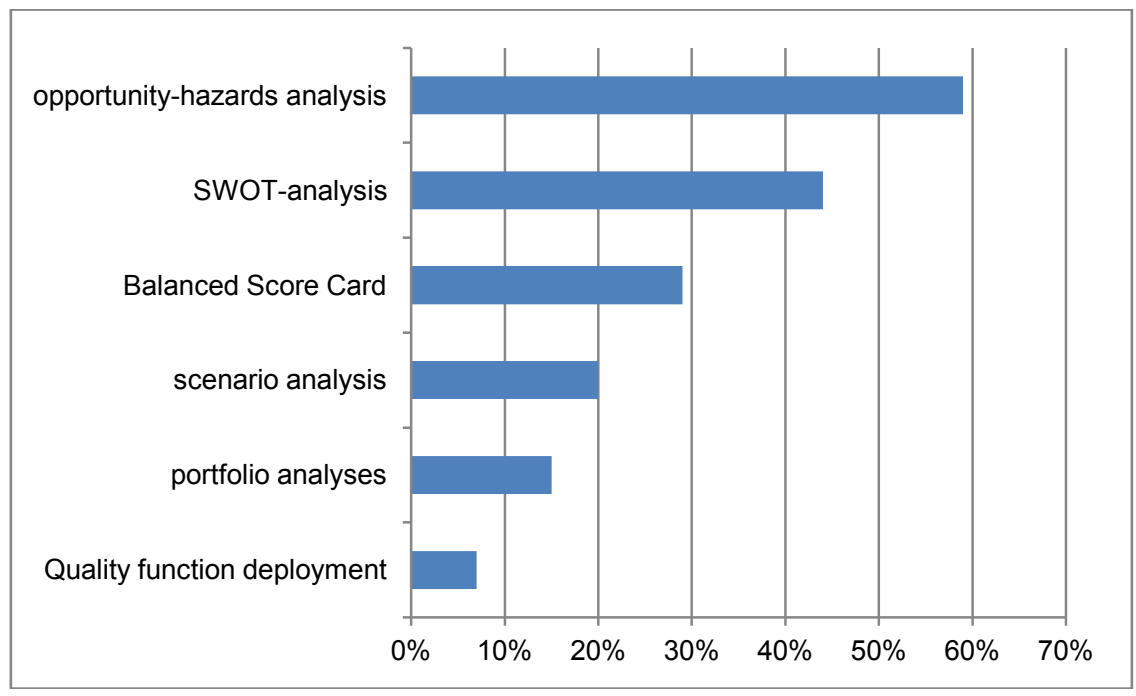

Figure 3: Strategic instruments.

Besides the previously mentioned methods for the operational RM process, there are various instruments and tools available, mostly from quality management (see figure 4). It was also examined what instruments are used in which phase of the RM process (see table 2).

Mainly instruments of a qualitative nature are common in practical application. The more complex a tool is the less its permeation.

Furthermore, the survey shows that the number of identified risks does not correlate with firm size (the number of identified risks is between 5 and 500). Nearly half of all respondents $(49 \%)$ indicate that they aggregate individual risks and re-use them in the form of compacted aggregate risks. The individual 
risks are often differently checked for actuality. The overwhelming majority of $59 \%$ control risk only once a year. $17 \%$ of companies look at their risks twice a year or quarterly.

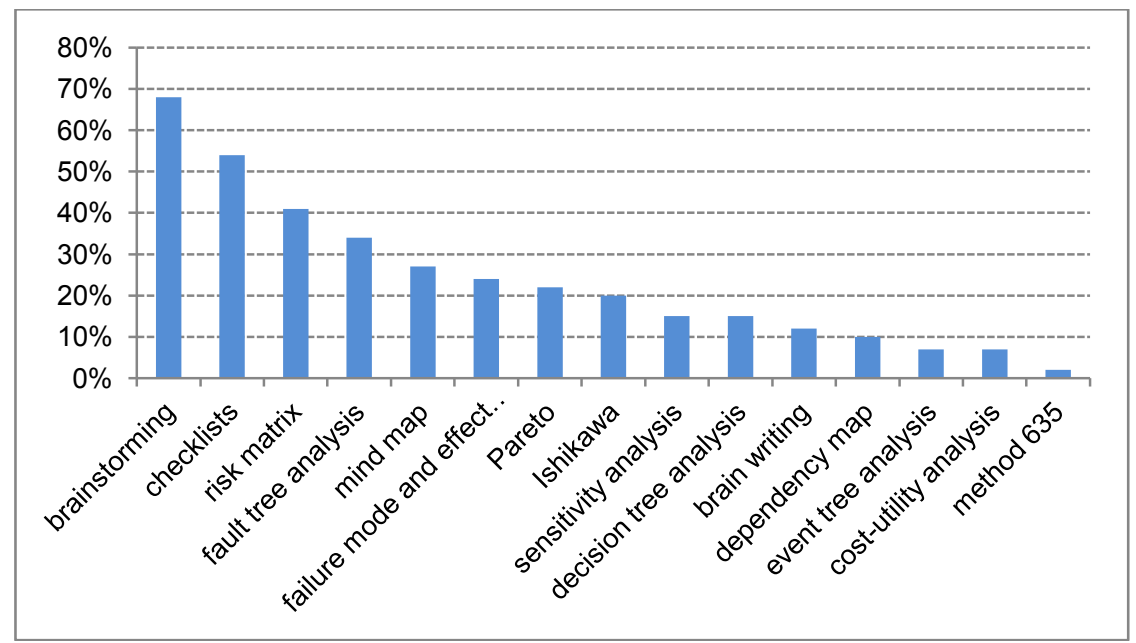

Figure 4: Operational instruments.

Table 2: $\quad$ Phase-related use of instruments.

\begin{tabular}{|c|c|c|c|c|}
\hline & 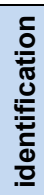 & 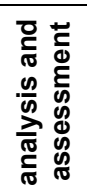 & $\begin{array}{l}\overline{0} \\
\text { 몽 } \\
\end{array}$ & 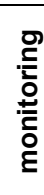 \\
\hline brainstorming & $\mathbf{x}$ & & & \\
\hline checklists & $\mathbf{x}$ & & $\mathbf{x}$ & $\mathbf{x}$ \\
\hline risk matrix & & $x$ & $\bar{x}$ & $x$ \\
\hline fault tree analysis & $\mathbf{x}$ & & $x$ & \\
\hline mind map & $\mathbf{x}$ & & & \\
\hline failure mode and effect analysis & $x$ & $x$ & $x$ & $\mathbf{x}$ \\
\hline Pareto & & $\mathbf{x}$ & & \\
\hline Ishikawa & $\mathbf{x}$ & $\mathbf{x}$ & & \\
\hline sensitivity analysis & & $\mathbf{x}$ & & \\
\hline decision tree analysis & & & $x$ & \\
\hline brain writing & $\mathbf{x}$ & & & \\
\hline dependency map & & $\mathbf{x}$ & & \\
\hline event tree analysis & & $x$ & $\mathbf{x}$ & \\
\hline cost-utility analysis & & $\mathbf{x}$ & & $\mathbf{x}$ \\
\hline method 635 & $\mathbf{x}$ & & & \\
\hline
\end{tabular}


The majority of companies $(76 \%)$ have their own corporate policy for the RM process. Slightly more than a half document their risks by using a central process. For example, the collection takes place by an own risk manager via interviews. A decentralized process, in which the departments document the identified risks independently, is performed in $46 \%$ of the companies.

\section{Risk documentation: an IT support}

Risk documentation is an essential task in the RM process as it applies to all process steps and exercises a control and information function. Systematic documentation allows avoiding future events. Furthermore, a plurality of tasks is carried out recurrently. This is due to the complexity and diversity of identifiable risks with simple word processing programs no longer being efficiently performable. By using appropriate software applications, it is possible to support the RM process over long distances.

Depending on company size, number of identified risks and analytical requirements, different software solutions are in use. By using software, risks can be easily categorized, structured, and monitored [7]. RM software systems were initially used in the financial sector. Because of changes in legal requirements these have become established in the industrial and service sector too [8]. Solutions are designed to help ensure a systematic and regular identification, assessment, control and monitoring of risk as well as to structure and automate this process. Especially careful archiving of processes, evaluations and decisions as well as the creation of compliant reports serve as a legal safeguard for decision makers. Offered RM information systems differ greatly in their analytical capabilities and reporting options. Basically, the software solutions can be divided into three groups, with only the last two being regarded as a RMIS in a narrower sense [9].

- Standard solutions are used among other things for RM. These are plain text and spreadsheet programs with appropriate add-ins that allow us to describe, aggregate, structure, detect and evaluate individual risks.

- Standardized special solutions for RM (and possibly rating) are mostly stand-alone programs and already geared to specific requirements.

- Integrated business intelligence solutions are individually designed to provide a large amount of reporting and control functions and are generally well integrated into the overall IT infrastructure.

According to a survey by Pricewaterhouse Coopers [10], 78\% of the companies use Microsoft Excel as a support system to manage their risks. These findings, also consistent with the results of this study, were that just over half (54\%) ever use software to support the RM process. While the used upcoming IT solution is that $62 \%$ use standard software such as a spreadsheet or word processing programs with appropriate add-ins. Standardized special software is used by $29 \%$ and an integrated business intelligence solution only by $10 \%$ of respondents. 


\section{Discussion}

In general, the identification and assessment of risks attached great importance in the RM process and identification as well as assessment are in large part on a regular basis, but with less methodical support. In particular, the consolidation and aggregation of the operative risk level in the strategic management is incomplete and fragmentary. Here, further research is needed in order to ensure a better integration.

The software support, especially in the area of risk documentation is still limited on the use of standard software solutions, such as programs for spreadsheets and word processing with appropriate add-ins. Only a small percentage of the companies surveyed use special software defined as an RM information system, which supports all phases of the RM process.

The recommendation for operational practice should be to support the RM process as a closed-loop with a matched set of instruments and to ensure the connection between the operational and strategic level. Only a consistent and quantifiable formulation of objectives and a derived risk strategy implementation, always in consultation with the corporate risk policy, leads to systematic management of a company's risks.

\section{Conclusion}

Increasing complexity and dynamism of the business environment but also the compulsion of raising efficiency, which is always associated with making internal systems lean, forces the need for a comprehensive and holistic RM system. Therefore we have to look, beside the financial and economic perspective, even to the value-added production and service processes with its resulting risks. The present study shows that just in those fields a systematic and consistent application of instruments and tools in the RM process is lacking in operational practice. These methodological gaps often lead to not closed RM process loops and to a missing connection from an operational to a strategic management level. Here it is important to use a matched set of instruments and tools in order to ensure a closed RM process, which in turn minimizes the uncertainty in dealing with risks.

\section{References}

[1] Romeike, R., Rühl, U., Risk Management to the test. Wissensmanagement, 5 (2009), p. 54, 2009.

[2] Romeike, R., Hager, P., Success factor risk management 2.0, Gabler Verlag: Wiesbaden, p. 111, 2009.

[3] Nevries, P., Strauß, E., Controlling tasks within the risk management process, Zeitschrift für Controlling \& Management, 52(2), p. 106, 2008.

[4] Herre, U., Tüllner, J., Crisis. Risk. Management. Frankfurt/Main, p.7, 2010. 
[5] Klügl, F., Economic performance risk control: instruments and methods used in operational processes, $\mathrm{PhD}$ thesis, Montanuniversität Leoben, p. 13, 2005.

[6] Wildemann, H., Management of economic risks in production, Zeitschrift für wirtschaftlichen Fabrikbetrieb, 4/2005, München, p. 190, 2005.

[7] Lowien, Th., Risk-structure determination by RM-EXPERT, Pastors, P.M. (Edt.): Risiken des Unternehmens - vorbeugen und meistern. München 2002, S. 586.

[8] Matt, Ch., Software for RM - IT-Solutions, Zeitschrift für Controlling \& Management, 53(5), p. 271, 2009.

[9] Gleißner, W., Romeike, F., Demands on the software support for risk management, Zeitschrift für Controlling \& Management, 49(2), p. 154-164, 2005.

[10] Schaffry, A., PWC-Study: Performance Management - Risk Management via MS Excel. URL: http://www.cio.de/subnet/oracle-data-expert/1932664/ (20.09.2010). 